\title{
SARS-CoV-2 vs smallpox: mass vaccinations in the mirror
}

\author{
Raffaella Bianucci ${ }^{1,2,3}$ - Andreas G. Nerlich ${ }^{4} \cdot$ Emanuele Cigliuti $^{5} \cdot$ Simon T. Donell ${ }^{6} \cdot$ Antonio Perciaccante $^{7,8}$
}

Received: 2 February 2021 / Accepted: 22 March 2021 / Published online: 13 April 2021

(c) Società Italiana di Medicina Interna (SIMI) 2021

\section{Dear Editor,}

Until now, the current pandemic of SARS-CoV-2 or COVID19 , if symptomatic, has caused 2.65 million deaths worldwide (March 15th 2021) [1]. Italy is one of the countries that has registered the most infections both during the first and second waves [1]. Health interventions, mitigating measures, e.g. isolation and social distancing, and travel restrictions have been introduced; nevertheless, within a national population of 59,991,186 individuals (August 1st 2020) [2], 3.22 million people tested positive to the virus, 2.59 million recovered, and 102,000 deaths have been so far associated with the disease [1].

The development and implementation of the newly developed vaccine against SARS-CoV-2 (December 27th 2020), in less than a year since the first registered case, is considered an epochal event. Called the V-Day (Vaccination-Day), it marks the launch of the anti-COVID-19 mass vaccination campaign in all countries of the European Community.

Despite the no-vax movements, anti-COVID-19 vaccination is having a great impact on the collective imagery; several parallels have been drawn with another epochal event; the early mass vaccination against smallpox. To underline the historic relevance of the smallpox vaccination and to

Raffaella Bianucci

raffaella.bianucci@unito.it; r.bianucci@warwcick.ac.uk

Andreas G. Nerlich

Andreas.Nerlich@extern.lrz-muenchen.de

Emanuele Cigliuti

emanuelecigliuti@me.com

Simon T. Donell

stdonel1280@btinternet.com

Antonio Perciaccante

antonioperciaccante@libero.it

1 Warwick Medical School, Biomedical Sciences, The University of Warwick, Coventry CV4 7AL, UK

2 Legal Medicine Section, Department of Public and Pediatric Sciences, The University of Turin, Turin, Italy actualise the importance of modern immunisation, a photographic replication of the canvas "La Vaccinazione nelle campagne" (Vaccination in rural areas) depicted by the Verism painter Demetrio Cosola (1851-1895) in 1894, has been undertaken (Fig. 1a, b).

Nowadays in Italy, the anti-COVID-19 vaccine is voluntary; the opposite for the smallpox vaccination campaign at the end of the nineteenth century [3]. The promulgation of the Law Crispi-Pagliani [3] set the beginning of the Italian health reform and imposed mandatory mass vaccination against smallpox.

After the proclamation of the Kingdom of Italy (17 March 1861 ), the country was poor with inadequate living conditions. In 1870 , the Italian population was only 28 million inhabitants and for more than $40 \%$ their income was insufficient to guarantee decent living conditions. The average life expectancy in 1861 was 29 years old (median between males and females) [4]. Mortality rate for children under 1-yearold, in 1863 , was $23.2 \%$, and the mortality of the under-five years old was $45 \%$ [4]. Sixty-three percent of the working force was occupied agriculture and $44 \%$ of the population lived in conditions of absolute poverty [4].

The houses were unhealthy, there was no drinking water in all areas of the country, and hygiene was poor. All these

3 UMR 7268, Laboratoire d'Anthropologie Bio-Culturelle, Droit, Etique and Santé (Adés), Faculté de Médecine de Marseille, Marseille, France

4 Institute of Pathology, Academic Clinic Munich-Bogenhausen, Munich, Germany

5 Art Director Project "Vaccinazione 2020", Rome, Italy

6 Norwich Medical School, University of East Anglia, Norwich, UK

7 Department of Medicine, "San Giovanni di Dio Hospital", Azienda Sanitaria Universitaria Giuliano Isontina, Gorizia, Italy

8 Laboratoire Anthropologie Archéologie Biologie (LAAB), UVSQ UFR Des Sciences de La Santé, Université Paris-Saclay, 2 Avenue de la Source de la Bièvre, 78180 Montigny-le-Bretonneux, France 

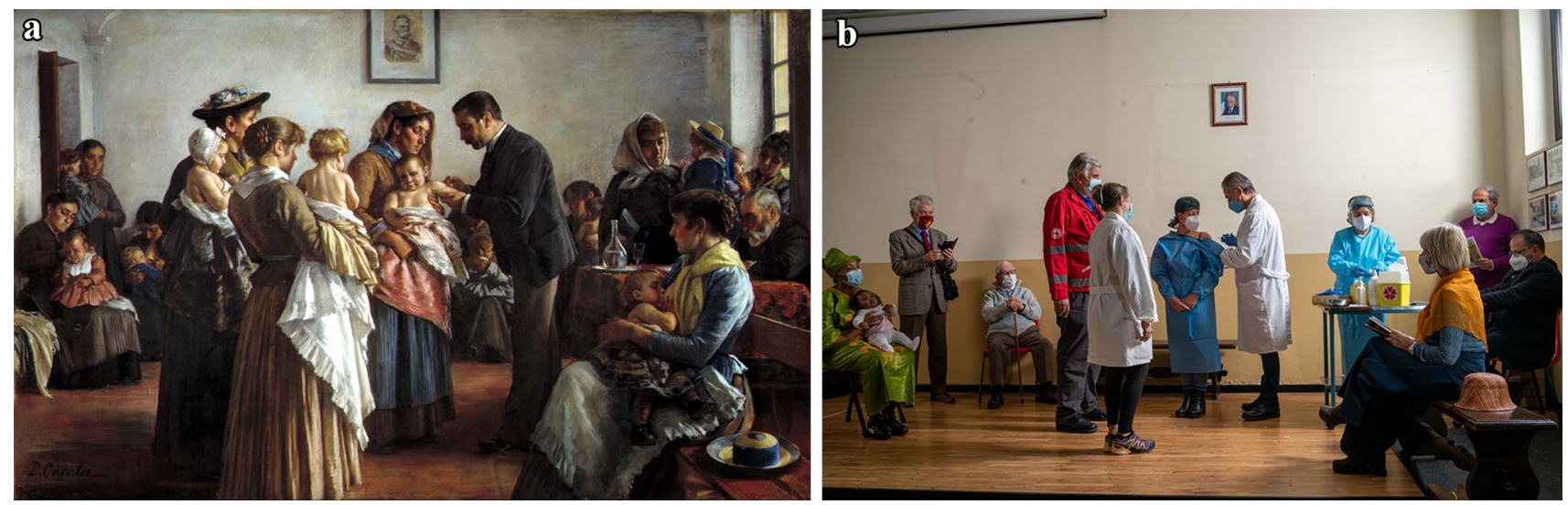

Fig. 1 a "La vaccinazione nelle aree rurali" by Demetrio Cosola. Per gentile concessione della città di Chivasso@; b the photographic remake by the Italian painter Massimiliano Modena in collaboration

factors together allowed epidemic and endemic diseases to thrive (tuberculosis, measles, pertussis, cholera, typhus, malaria, syphilis, smallpox, diphtheria). In 1861, almost $30 \%$ of the global deaths were caused by infectious diseases, followed by respiratory diseases (bronchitis, pneumonia $=25 \%$ of the total), cardiovascular diseases, gastroenteric diseases and cancer. Rickets and pellagra, due to malnutrition, were also extremely widespread [4]. Early vaccination campaigns were first carried out in the army and, then, in the cities and in the rural areas, with the aim of protecting the highest number of susceptible individuals in a shortest time span. Two years after the introduction of the health reform (1889-1890), a series of implementing decrees were drawn up in each sector of public hygiene: mortuary police, maritime health, soil hygiene, and house hygiene. Physicians were paid by the state and provided free care to population [4].

The Health Assistance Law of December 221888 (n. 5849) made it compulsory to report the cause of death of each citizen to the Mayor of each Municipality. Therefore, from 1889 onward, a systematic data collection was mandatory. In a country still decimated by endemic and epidemic diseases, the Law Crispi-Pagliani ordered each Municipality to declare the presence of contagious diseases, introduce mandatory vaccinations, provide clean waters through the construction of aqueducts, and the compilation of health statistics. Obviously, the Law Crispi-Pagliani did not solve all the health problems of the times; however, progress was remarkable and immediate [3]. The smallpox vaccination campaign in Italy was highly successful. Between 1888 and 1925 , the number of smallpox registered cases dropped dramatically. In 1920 , there were 26,000 cases that dropped to 4000 in 1921 and to 206 in 1925 . The vaccination against smallpox was compulsory until 1981 because of the presence of the disease in other areas of the world (i.e. Africa). with the Italian Red Cross. Emanuele Cigliuti @-_art director; Massimiliano Modena $\odot$ _ photographer. Reproduced with permission

However, by 1977, the smallpox vaccination had actually already been suspended $[5,6]$.

Following the laws imposed by the Government Crispi, the Municipality of Chivasso was the first town in Piedmont where the vaccination campaign started and was extended to the rural areas. The real revolution consisted in the fact that all Municipalities were compelled to employ and pay a local doctor ("medico condotto") who had to guarantee free medical assistance to all citizens [3].

In the canvas "La Vaccinazione nelle aree rurali" (Fig. 1a), the painter Demetrio Cosola depicts a powerful communal scene. The local physician (without a gown) injects the vaccine into the arm of a weeping child, who is kept in his mother's arms. Behind the mother, several women wait their turn with their children partially undressed. The room where the scene takes place is most likely a doctor's office, filled with mothers waiting for their children's vaccination. To be realistic, the models depicted in Cosola's canvas were chosen from the citizens of Chivasso. The physician is set in a central position, to underline the importance of medicine in the fight against infectious diseases. The scene is drawn to give the viewer the impression of a massive participation of the population, especially from the mothers' point-of-view, in an event that would have saved their children's lives.

If the scene depicted in the canvas is compared with its current photographical replica (Fig. 1b) striking differences emerge. The photograph shows that the target of the infection has changed. Instead of mothers with children, the picture is populated by older people, hospital personnel, including a volunteer of the Italian Red Cross, and a mother with her child. Social distancing rules are in place. The physicians wear gowns, gloves and masks, symbol of the progress of infectious disease precautions. Vaccination is administered first to a woman, a physician, while the other 
patients, essentially older people wearing masks are waiting for their turn.

SARS-CoV-2 is a viral disease whose target is different from late nineteenth century smallpox. The highest number affected in Italy has been registered among the elderly (median age 82 years). SARS-CoV-2 patients are, on average, 30 years older than infected patients with non-lethal outcomes (lethal median age, 82 years old compared to nonlethal median age at 48 years old). Age at death in SARS$\mathrm{CoV}-2$ positive patients is slightly higher in women than in men (medium age women 85, men 80). The highest burden has been registered in nursing homes. Here, the prevalence of chronic disease, which may impair the immune system, is high, and this, presumably, has an impact on the mortality rates [7].

However, the two images also show a similarity; regardless of the age class, both images capture the hope and need of individuals to "protect" themselves from the outcomes of a disease putting their lives at risk. Both images underly the importance of medical treatments in the fight against highly lethal pathogens, and the trust that the vast majority of the population has in medicine.

Society is at the threshold of a huge vaccination campaign against SARS-CoV-2, which is hoped to suppress the virus in the near future. The success of this campaign, and the speed of any protective progress, is, however, largely dependent on the number of vaccinated individuals in the global population. In this regard, it has to be hoped that the anti-COVID-19 vaccination campaign will have the same positive effects that occurred in nineteenth century Italy.

A significant threat to the success of mass vaccination against SARS-CoV-2 is represented by anti-vax movements that cast doubts on the efficacy of the procedure demonstrating a general mistrust in science. It should be emphasised that anti-vax movements are not a contemporary phenomenon.

They were present in Europe as early as the turn of eighteenth and nineteenth centuries when smallpox vaccination started. The opposition was particularly strong in the UK since the vaccination against smallpox became compulsory for newborn and infants (Vaccination Act, 1853). Anti-vax associations were created and public demonstrations were organised. The series of engravings entitled "The cowpock-or-the wonderful effects of the new inoculation" by James Gillray (1802, June 12th) are a clear example of the caricature of the vaccination scene at the Smallpox and Inoculation Hospital St. Pancras. The scene shows Dr Jenner vaccinating a frightened woman who is surrounded by people with cows emerging from different part of the bodies [8].

No-vax movements appeared in almost all countries. In Italy, the first organised anti-vax movement dates back to the introduction of mandatory mass vaccination against smallpox at the end of the nineteenth century. Claims of violation of individual rights were also raised by physicians and hygienists such as Carlo Ruata, Professor of Hygiene at the University of Perugia, who became the founder and the leader of the Italian League against vaccinations [9].

Both in the recent past and in modern days, doubts were raised against the potential damages caused to health by vaccines. They were considered as cocktails of toxic chemical compounds containing mercury, aluminium, formaldehyde and such as, because of their incapacity to confer permanent immunisation, and their possible role in activating other diseases, such as autism, allergies, Crohn's disease, and cancer. Fake news quickly spread giving rise to conspiracy theories following which viruses such as SARS-CoV-2 was intentionally created and intentionally spread all over the world for political/economic reasons. These misleading approaches to basic, scientific knowledge, have led to "vaccine hesitancy", the delay in accepting or refusing vaccination, independently from the availability of vaccines. These delays impair the fight against the global contagion thus reducing the efficacy of the vaccination campaigns [10].

Our paper underlines parallelisms between the early smallpox vaccination campaign and the ongoing one against SARS-CoV-2. However, there are also substantial differences between these vaccines. First, they are developed in different historical periods and with different techniques. The vaccine against smallpox is a live-attenuated vaccine; whereas, the vaccines against SARS-CoV-2 are nucleic acid or viral-vectored. More interestingly, they lead to two different types of immunity. Historically, the smallpox vaccination has been effective in preventing smallpox infection in $95 \%$ of those vaccinated [11]; the smallpox/variola vaccine was proven to caused sterilising immunity (i.e. that the antibodies generated clear the virus from the human body entirely by neutralising antibodies). However, the current evidence cannot tell us if vaccination against SARS CoV-2 can hinder its transmission (i.e. it is not known, if this can protect against the spread of the infection), even though it is known to block symptoms from appearing. As a result, vaccinated people can unknowingly carry and spread pathogens andoccasionally - they can even start epidemics [such as seen in the 2009 Ocean and Orange County outbreak of mumps virus from students that had received a full course of the measles, mumps and rubella-(MMR vaccine)] [12].

Taking these observations together, we can conclude that possible differences in "only" neutralising versus "sterilising" immunity need to be further clarified [13]; accordingly, more data will show whether the immune system may thwart infections entirely, and even prevent asymptomatic cases. There exists first evidence that the vaccines against SARSCoV-2 that point out that they cause an "effective immunity" because they may prevent a serious disease due to the virus, but they cannot prevent the virus from entering the body and replicating itself. Data from vaccines trials do not 
address whether vaccination prevents asymptomatic infection [14-16]. So, vaccinated people, as well as asymptomatic, can carry and spread SARS-CoV-2. In this context, it is essential that vaccinated people continue to respect the use of facemasks, hand hygiene, and social distancing, to avoid unwittingly spreading the virus. Whether compulsory measures used to immunise the late nineteenth century populations should be instituted today is a matter of fierce political and ethical debate.

Funding None.

\section{Declarations}

Conflict of interest All authors declare no conflict of interest.

Ethics approval No Ethics approval is needed here.

Ethical Statements There is no ethical statement to perform since no patient was involved in this study.

Consent to participate No human nor animals were tested and hence no informed consent was needed.

\section{References}

1. Ministero della Salute, Nuovo coronavirus. http://www.salute.gov. it/portale/nuovocoronavirus/dettaglioContenutiNuovoCoronav irus.jsp lingua $=i$ taliano $=5338 \&$ are $a=$ nuovoCoronavirus $\& m e n u=$ vuoto. Accessed 4 Mar 2021

2. Istituto Nazionale di Statistica. https://www.istat.it/it/archivio/ demografia. Accessed 4 Mar 2021

3. Law Crispi-Pagliani (1888) "Sulla tutela della igiene e della sanità pubblica", L. n. 5849, 22 December
4. Atella S, Francisci S, Vecchi G (2011) La salute degli Italiani, 1861-2011. Politiche Sanit 12(4): 167 (170-171, 174-176)

5. Belfanti S (1928) Terapia, vol 18 and 19. Istituto Sieroterapico Milanese, Milano, p 296

6. Galassi FM (2017) Un mondo senza vaccini? La vera storia. Gruppo C1V Edizioni

7. Epicentro. L'epidemiologia per la sanità pubblica Istituto Superiore di Sanità. https://www.epicentro.iss.it/coronavirus/sars-cov2-decessi-italia. Accessed 4 Mar 2021.

8. Library of Congress Prints and Photographs Division Washington, DC 20540, USA. http://hdl.loc.gov/loc.pnp/pp.print Accessed 4 Mar 2021

9. Tognotti E (2020) Vaccinare i bambini tra obbligo e persuasione: tre secoli di controversie Il caso dell'Italia. Fanco Angeli Editore

10. Galassi M, Varotto E (2019) Fake news in medicina: un grave deficit di conoscenza storico-medica e paleopatologica alla base del problema. Evidence 11(1):e1000192

11. Metzger W, Mordmueller BJ, Cochrane Infectious Diseases Group (2007) Vaccines for preventing smallpox. Cochrane Database Syst Rev 2007(3):CD004913

12. Centre of Disease Conrol (2009) Mumps outbreak-New York, New Jersey, Quebec, 2009. MMWR 58:1-4

13. Kennedy RB, Ovsyannikova IG, Jacobson RM, Poland GA (2009) The immunology of smallpox vaccines. Curr Opin Immunol. 21(3):314-320

14. Polack FP, Thomas SJ, Kitchin N et al (2020) Safety and efficacy of the BNT162b2 mRNA COVID-19 vaccine. N Engl J Med 383:2603-2615

15. Baden LR, El Sahly HM, Essink B et al (2021) Efficacy and safety of the mRNA-1273 SARS-CoV-2 vaccine. N Engl J Med 384:403-416

16. Voysey M, Clemens SAC, Madhi SA et al (2021) Safety and efficacy of the ChAdOx1 nCoV-19 vaccine (AZD1222) against SARS-CoV-2: an interim analysis of four randomised controlled trials in Brazil, south Africa, and the UK. Lancet 397(10269):99-111

Publisher's Note Springer Nature remains neutral with regard to jurisdictional claims in published maps and institutional affiliations. 